\title{
Prevalence and molecular typing of Giardia duodenalis in wildlife from eastern Poland
}

\author{
Krzysztof Stojecki $^{1}$, Jacek Sroka ${ }^{1,2}$, Simone M. Cacciòn ${ }^{3}$, Tomasz Cencek ${ }^{1}$, Jacek Dutkiewicz $^{2}$ and Pawel Kusyk ${ }^{1}$ \\ ${ }^{1}$ Department of Parasitology, National Veterinary Research Institute, Pulawy, Poland; \\ ${ }^{2}$ Department of Health Biohazards and Parasitology, Institute of Rural Health, Lublin, Poland; \\ ${ }^{3}$ Department of Infectious, Parasitic and Immunomediated Diseases, Istituto Superiore di Sanità, Rome, Italy
}

\begin{abstract}
Faecal samples from 162 wild animals were collected from 32 distinct sites of Łęczyńsko-Włodawskie Lakeland (eastern Poland). The presence of Giardia duodenalis (Stiles, 1902) was assessed by a Direct Fluorescence Assay (DFA) and by Polymerase Chain Reaction (PCR) and sequencing of a fragment of the beta-giardin gene. DFA showed the presence of cysts of G. duodenalis in 12 of 162 faecal samples (7\%), namely in four wild boars (15\%), four foxes (19\%), two roe deer (4\%), and two wolves (29\%). PCR identified 34 of the $162(21 \%)$ samples as positive, including 11 wild boars $(41 \%)$, five red deer $(18 \%)$, 11 roe deer $(23 \%)$, four moose $(17 \%)$, two wolves (29\%) and a single sample from the European badger. Thus, PCR detected a significantly higher number of infection than DFA ( $\mathrm{P}=0.0005)$. However, 14 of $34 \mathrm{PCR}$ products could not be sequenced because of their insufficient amount; the low number of cysts, poor conservation of the faeces or presence of PCR inhibitors may have contributed to weak DNA amplification. Sequence analysis of the remaining 20 products showed the presence of assemblage B in wild boars, red deer and roe deer, whereas samples from wolves were identified as assemblage D. This is the first detection of assemblage B in wild boars and deer. As assemblage B has zoonotic potential, wild animals from eastern Poland may act as reservoirs of cysts of G. duodenalis infectious for humans.
\end{abstract}

Keywords: parasitic protists, wild animals, faecal samples, zoonotic transmission, Direct Fluorescence Assay, PCR

Giardia duodenalis (Stiles, 1902 ) (syns. Giardia intestinalis Kulda et Nohýnková, 1996, Giardia lamblia Kofoid et Christiansen, 1915) is an important causative agent of diarrhea in humans and in many species of animals, including livestock, pets and wildlife (Feng and Xiao 2011). The life cycle of this parasite includes only two stages: the infective cyst and the trophozoite. Transmission can be direct, through the faecal-oral route, or indirect, through ingestion of contaminated water and food (Adam 2001). In humans, symptomatic infection presents with diarrhea, greasy stools, flatulence and abdominal cramps, but a high number of cases are asymptomatic. Infection in young children has been associated with poor cognitive function and stunted growth (Berkman et al. 2002).

Direct microscopic examination of faecal smears from fresh or concentrated samples (either unstained or after Giemsa or Lugol's iodine staining) is still widely used to detect cysts in faeces. These methods are relatively simple and inexpensive, but require an experienced microscopist for correct interpretation. The gold standard in diagnostics of Giardia spp. is the Direct Fluorescence Assay (DFA). DFA utilises fluorescent-labelled antibodies directed against cyst wall antigens to stain of $G$. duodena$l i s$, allowing their identification using an epifluorescence microscope. Many commercial DFA kits are available and are more sensitive than conventional staining techniques (Veronesi et al. 2010). Enzyme immunoassay and rapid immune-chromatographic cartridge assays also are available, but may generate false positive or false negative results in cases of chronic or mild infection (Hanson and Cartwright 2001, Weitzel et. al. 2006). Molecular assays, e.g. Polymerase Chain Reaction (PCR), show high sensitivity and specificity and have the advantage that they allow identification of species of Giardia or their assemblages (Read et al. 2004). It must be remembered, however, that many matrices, including faeces, contain PCR inhibitors (Schrader et al. 2012).

Eight assemblages of G. duodenalis (A-H) have been identified, of which two (A and B) infect humans and other mammals, whereas assemblages $\mathrm{C}-\mathrm{H}$ appear to be strictly host-specific (Ryan and Cacciò 2013). No morphological variation has been observed among isolates belonging to different assemblages and thus their identification requires the use of molecular methods.

There are numerous reports of the occurrence of assemblages A and B in both domesticated (livestock, dogs and cats) and wild animals (non-human primates, beavers, marsupials, rodents). This suggests the potential for 
zoonotic transmission. However, only a few studies in endemic countries have shown a role of dogs or cattle in the transmission of giardiasis to humans (Traub et al. 2004, Khan et al. 2011).

To our knowledge, data on the prevalence of infection with $G$. duodenalis among wildlife in central and eastern Europe are very scarce and are often based on microscopical or serological investigations without the use of molecular techniques (Bajer 2008). Therefore, the aim of the present study was to estimate the prevalence of $G$. duodenalis among selected species of wild animals from eastern Poland (Łęczyńsko-Włodawskie Lakeland), and to characterise isolates found molecularly.

\section{MATERIALS AND METHODS}

Faecal samples from 162 animals were collected at three distinct sites of Łęczyńsko-Włodawskie Lakeland (eastern Poland) from November 2012 to March 2013. Samples originated from 27 wild boars Sus scrofa Linnaeus, 28 red deer Cervus elaphus Linnaeus, 48 roe deer Capreolus capreolus (Linnaeus), 23 moose Alces alces (Linnaeus), 21 foxes Vulpes vulpes (Linnaeus), seven wolves Canis lupus (Linnaeus), four European hares Lepus europaeus Pallas, one otter Lutra lutra (Linnaeus), one European badger Meles meles (Linnaeus), one weasel Mustela sp., and one marten Martes sp. Faecal samples were assigned to species by the authors, using specialised literature and the assistance of foresters and/or hunters. Samples were stored at $4-8^{\circ} \mathrm{C}$ until further analysis.

One gram of faeces was mixed with $8 \mathrm{ml}$ of a $25 \%$ Percoll solution and filtered through a plastic sieve into a beaker. The suspension was poured into a $15 \mathrm{ml}$ conical centrifuge tube and centrifuged at $1600 \mathrm{~g}$ for $5 \mathrm{~min}$. According to the volume of sediment obtained, threefold volumes of saturated $\mathrm{NaNO}_{3}$ were added to the sediment, which was then mixed and centrifuged at $1000 \mathrm{~g}$ for $10 \mathrm{~min}$. Then, $200 \mu \mathrm{l}$ were removed from the top layer, placed in a new $15 \mathrm{ml}$ conical centrifuge tube and washed by centrifugation $(1100 \mathrm{~g} \times 10 \mathrm{~min})$ in $13 \mathrm{ml}$ redistilled water. The sediment was stored at $4{ }^{\circ} \mathrm{C}$ until further analysis (Stojecki et al. 2014).

DFA was performed using a commercial kit (Aqua-Glo ${ }^{\mathrm{TM}}$, Waterborne Inc., New Orleans, USA) according to the manufacturer' instructions. The concentrated sediment $(25 \mu 1)$ obtained by the isolation procedure described above, was examined under an epifluorescence microscope at $400 \times$ magnification. Cysts of Giardia duodenalis were identified based on their size, shape and structure according to the guidelines described in method 1623 (US Environmental Protection Agency Method 1623). Positive and negative controls were included. The entire slide was observed to estimate the number of cysts present.

Two hundred microlitres of concentrated sediment were used for DNA extraction. After seven cycles of freezing and thawing (liquid nitrogen followed by heating at $65^{\circ} \mathrm{C}$ ), DNA was extracted using the QIAamp ${ }^{\circledR}$ DNA Mini Kit (Qiagen GmbH, Hilden, Germany) according to the manufacturer's instructions, except for an overnight incubation with proteinase $\mathrm{K}$. The extracted DNA was stored at $-20^{\circ} \mathrm{C}$ until PCR assay. PCR amplification of a $384 \mathrm{bp}$ fragment of the beta-giardin $(b g)$ gene was performed according to a published procedure (Cacciò et al. 2002), with minor modifications. Each reaction mixture $(50 \mu \mathrm{l})$ contained $10 \mathrm{pmol}$ of each primer, $0.2 \mathrm{mM}$ of each dNTP (Fermentas, Vilnius, Lithuania),
$50 \mathrm{mM} \mathrm{KCl}, 10 \mathrm{mM}$ Tris- $\mathrm{HCl}$ ( $\mathrm{pH} 9.0$ ), $2 \mathrm{mM} \mathrm{MgCl}$, $1.5 \mathrm{U}$ of Taq DNA polymerase (Qiagen $\mathrm{GmbH}$ ) and 1-2 $\mu 1$ of DNA. Amplification was performed using a TProfessional 48 thermal cycler (Biometra $\mathrm{GmbH}$, Göttingen, Germany) as follows: an initial cycle at $94^{\circ} \mathrm{C}$ for $5 \mathrm{~min}$, followed by 35 cycles of $94^{\circ} \mathrm{C}$ for $30 \mathrm{~s}, 65^{\circ} \mathrm{C}$ for $30 \mathrm{~s}$, and $72^{\circ} \mathrm{C}$ for $60 \mathrm{~s}$. Final extension was done at $72{ }^{\circ} \mathrm{C}$ for $7 \mathrm{~min}$. Each semi-nested PCR product was analysed by gel electrophoresis $(1.5 \%$ agarose gel stained with ethidium bromide). Negative and positive controls were included in each PCR reaction.

PCR products were purified by spin column (QIAquick purification kit, Qiagen $\mathrm{GmbH}$ ), and sequenced on both strands using the BIGDYE Cycle Sequencing Kit (Life Technologies, Carlsbad, CA, USA), according to the manufacturer's instructions. Chromatograms were examined using BioEdit (http://www.mbio. ncsu.edu/BioEdit/). Nucleotide sequences were compared with those available in the GenBank database using BLAST (http:// www.ncbi.nlm.nih.gov/blast/).

Selected nucleotide sequences have been deposited in the GenBank database under the accession numbers: KF736103KF736113.

Differences between the frequency of the detection of cysts of $G$. duodenalis by microscopy and PCR were assessed by Student's t-test using STATISTICA v. 5.1 package (Statsoft, Tulsa, OK, USA).

\section{RESULTS}

Cysts of Giardia duodenalis were detected in 12 of 162 faecal samples (i.e. in 7\%). Positive specimens were from wild boars ( 4 of $27,15 \%$ ), foxes ( 4 of $21,19 \%$ ), roe deer ( 2 of $48,4 \%$ ) and wolves ( 2 of 7, 29\%). The number of cysts in these samples was small (less than ten cysts), except for samples derived from wolves, in which a dozens of cysts were observed. Faecal samples from red deer, moose, European hares, otter, European badger, weasel and marten were negative.

Amplification of a $384 \mathrm{bp}$ fragment of the $b g$ gene was obtained from 34 of the 162 (21\%) samples. Therefore, a significantly higher number of positive samples were detected using PCR than DFA $(\mathrm{P}=0.0005)$. Positive samples were from wild boars ( 11 of $27,41 \%)$, red deer ( 5 of $28,18 \%$ ), roe deer (11 of $48,23 \%$ ), wolves ( 2 of $7,29 \%$ ), moose ( 4 of $23,17 \%$ ) and the single sample from a European badger. Samples from foxes were PCR negative.

Of the 34 PCR positive samples, 20 (59\%) were successfully sequenced, whereas the remaining 14 samples yielded products that were insufficient for DNA sequencing. The results of DFA and molecular analysis are summarised in Table 1.

Sequence analysis identified the samples derived from wild boars, red deer and roe deer as assemblage B. The most common sequence was found in samples from four roe deer, two red deer and two wild boars, and was identical to the reference sequence LD18 (GenBank accession number AY072726), a representative of sub-assemblage BIII. The remaining seven different $b g$ sequence types showed one- or two-single nucleotide polymorphisms from LD18, and were found in single samples from three wild boars (three different sequence types), three roe deer 
Table 1. Prevalence and genotyping of 162 wild isolates of Giardia duodenalis (Stiles, 1902) based on Direct Fluorescence Assay (DFA) and Polymerase Chain Reaction (PCR).

\begin{tabular}{lccc}
\hline Host & DFA & PCR & Isolate sequenced [assemblage] \\
\hline Wild boar (Sus scrofa Linnaeus) & $4 / 27^{*}(15 \%)$ & $11 / 27(41 \%)$ & $6 / 27(22 \%)[\mathrm{B}]$ \\
Red deer (Cervus elaphus Linnaeus) & $0 / 28$ & $5 / 28(18 \%)$ & $4 / 28(14 \%)[\mathrm{B}]$ \\
Fox [Vulpes vulpes (Linnaeus)] & $4 / 21(19 \%)$ & $0 / 21$ & \\
Moose [Alces alces (Linnaeus)] & $0 / 23$ & $4 / 23(17 \%)$ & \\
Roe deer [Capreolus capreolus (Linnaeus)] & $2 / 48(4 \%)$ & $11 / 48(23 \%)$ & $2 / 48(17 \%)[\mathrm{B}]$ \\
Wolf (Canis lupus Linnaeus) & $2 / 7(29 \%)$ & $2 / 7(29 \%)$ & \\
European hare (Lepus europaeus Pallas) & $0 / 4$ & $0 / 4$ & $0 / 1$ \\
Otter [Lutra lutra (Linnaeus)] & $0 / 1$ & $0 / 1$ & \\
European badger [Meles meles (Linnaeus)] & $0 / 1$ & $1 / 1$ & \\
Weasel (Mustela sp. Linnaeus) & $0 / 1$ & $0 / 1$ & \\
Marten (Martes sp. Pinel) & $0 / 1$ & $0 / 1$ & $20 / 162(12 \%)$ \\
\hline Total & $12 / 162(7 \%)$ & $34 / 162(21 \%)^{* *}$ & \\
\hline
\end{tabular}

*infected/examined; ***tatistically significant difference $(\mathrm{P}=0.0005)$

(three different sequence types) and one red deer (one sequence). The widespread distribution of assemblage $B$ in the Łęczyńsko-Włodawskie Lakeland is indicated by the presence of an identical $b g$ sequence in samples collected from distinct sampling sites.

Two samples from wolves were classified as assemblage D and were identical to that from a dog (AY545647). The two samples from wolves were collected at the same sampling site, from the same pack of wolves.

\section{DISCUSSION}

Giardiasis is a public health problem in Poland. During 2004-2008, the average number of cases per year was close to 3000 , as reported by the National Institute of Public Health - National Institute of Hygiene (NIPH-NIH 2014) (Wojtyniak et al. 2012). In the Lubelskie region, which comprises the Łęczyńsko-Włodawskie Lake District, the average number of cases of giardiasis per year was 237 in the same period. It is likely that the prevalence of Giardia duodenalis is strongly underestimated as only severe cases are properly diagnosed. It is also worth mentioning that about two thirds of the patients with giardiasis needed hospitalisation (NIPH-NIH 2004-2014). So far, little is known about transmission routes of giardiasis in Poland. Many studies have documented the occurrence of species of Giardia in the environment (Adamska 2015) and in domestic and wild animals (Bednarska et al. 2007, Bajer 2008), but only a few have included a molecular characterisation of the parasite.

Here we provided new data about the occurrence of G. duodenalis among wild animals in the LęczyńskoWłodawskie Lakeland of Poland. This region is an example of a rural area rich in watercourses and swamps, thus representing an environment suitable for the spread of the parasite. There are numerous lakes, surrounded by peat bog and forest. The area is protected as nature reserves, sites within national park and ecological lands. Moreover, it is an extremely popular touristic destination (Chmiel 2009, Krukowska and Krukowski 2009) and humans are potential contributors to environmental contamination and spread of pathogens.
Using a DFA assay, $12(7 \%)$ samples were positive for G. duodenalis, whereas 34 (21\%) samples were positive by PCR; this difference was statistically significant. It should be recalled, however, that faeces were processed to isolate cysts of G. duodenalis prior to DFA or PCR, and that samples containing very few and/or damaged cysts could have been classified as negative. Therefore, the prevalence data reported here should be considered with caution. DFA detected cysts of G. duodenalis in wild boars, foxes, roe deer and wolves, whereas PCR was positive for samples from wild boars, red deer, moose, roe deer, wolves and European badger. The number of cysts was generally quite low (less than ten cysts per slide); this may reflect an asymptomatic infection or carriage of $G$. duodenalis, which occurs frequently among animals (Rimhanen-Finne et al. 2007).

The overall prevalence in wild boars was $41 \%$, which is higher than values $(0-1.7 \%)$ reported in other studies (Paziewska et al. 2007, Beck et al. 2011, Castro-Hermida et al. 2011). We identified assemblage B in wild boars for the first time. While this assemblage has been detected in swine (Farzan et al. 2011), only assemblage A was identified in a wild boar from Croatia (Beck et al. 2011).

The estimated prevalence of $G$. duodenalis in red deer and roe deer was $18 \%$ and $23 \%$, respectively. Epidemiological studies in Poland have shown a similar prevalence (Paziewska et al. 2007, Solarczyk 2009). Worldwide, the prevalence among wild cervids ranges between 1 and 24\%, with no obvious correlation with the different deer species examined (Rickard et al. 1999, Robertson et al. 2007, Beck et al. 2011). So far, only assemblage A has been found among cervid species; therefore this study is the first to report the presence of assemblage B in these hosts.

Few investigations have focused on the occurrence of $G$. duodenalis in red foxes. In Norway, Hamnes et al. (2007) detected cysts of $G$. duodenalis in 13 of 269 red foxes $(5 \%)$, and identified both assemblages A and B. A recent study in Croatia also reported a similar prevalence, $5 \%$ (Beck et al. 2011). In our study, DFA showed the presence of cysts in four samples from foxes, but PCR failed to detect DNA of $G$. duodenalis. However, DNA degradation in these samples was suggested by the lack of staining of the nuclei, which can explain the negative PCR results. 
In the samples derived from moose and from a European badger, PCR gave positive results whereas DFA was negative. Unfortunately, weak amplification prevented the possibility to characterise these samples at the DNA level. So far, assemblage A has been described in the moose (Hamnes et al. 2006), whereas no information is available on G. duodenalis in European badgers.

Our study is one of the few that characterised G. duodenalis from wolves at the molecular level. Previous studies based on microscopy showed a prevalence of $46 \%$ (Kloch et al. 2005) and 20\% (Bednarska et al. 2007) in wolves from Poland. In our study, we observed a lower prevalence, but a smaller number of animals were tested. The molecular analysis identified assemblage D in two wolves. In a study conducted in Croatia, multi-locus genotyping showed mixed infection of wolves with assemblages A and D (Beck et al. 2011).

Samples from European hares, otter, weasel and marten were negative for $G$. duodenalis. The presence of assemblage A has been reported previously in ferrets (Mustela putorius furo Linnaeus) in Japan (Abe et al. 2010).

The present study has some limitations. First, stool samples were collected directly from the environment and, albeit sampling sites were several kilometers apart from each other, we cannot exclude that some of the samples may originate from the same animal. Second, the limited number and poor conservation status of cysts in most samples hampered a more detailed molecular characterisation of parasites found, which was limited to a single marker. Since mixed infections and/or discordant assignment to assemblages have been reported in isolates from wild animals and their detection requires the use of multiple markers (Beck et al. 2011), the zoonotic potential inferred in this study must be confirmed by larger surveys.

Finally, the question of how wild animals were infected with $G$. duodenalis assemblage B remains open. As mentioned above, Łęczyńsko-Włodawskie Lakeland of Poland is an important touristic destination and thus an area of intense human activities. The possibility of 'reverse zoonotic', i.e. that human contamination was the source of infection for animals (Khan et al. 2011), and the impact humans may have on wildlife health should be considered in future studies.

Acknowledgements. The presented results was conducted in the frame of $\mathrm{PhD}$ studies of K. S. ('Occurrence of Giardia duodenalis among humans and selected species of livestock and wildlife in Leczynsko-Wlodawskie Lake District', National Veterinary Research Institute in Pulawy, Poland).

\section{REFERENCES}

Abe N., Tanoue T., Noguchi E., Ohta G., Sakai H. 2010: Molecular characterization of Giardia duodenalis isolates from domestic ferrets. Parasitol. Res. 106: 733-736.

AdAm R.D. 2001: Biology of Giardia lamblia. Clin. Microbiol. Rev. 14: 447-475.

AdAMSKa M. 2015: Molecular characterization of Cryptosporidium and Giardia occurring in natural water bodies in Poland. Parasitol. Res. 114: 687-692.

BAJer A. 2008: Cryptosporidium and Giardia spp. infections in humans, animals and the environment in Poland. Parasitol. Res. 104: 1-17.

Beck R., Sprong H., Lucinger S., Pozio E., Cacciò S.M. 2011: A large survey of Croatian wild mammals for Giardia duodenalis reveals a low prevalence and limited zoonotic potential. Vector-Borne Zoon. Dis. 11: 1049-1055.

Bednarska M., Bajer A., Siński E., Girouard A.S., Tamang L., Graczy T.K. 2007: Fluorescent in situ hybridization as a tool to retrospectively identify Cryptosporidium parvum and Giardia lamblia in samples from terrestrial mammalian wildlife. Parasitol. Res. 100: 455-460.

Berkman D.S., Lescano A.G., Gilman R.H., Lopez S.L., BLACK M.M. 2002: Effects of stunting, diarrhoeal disease, and parasitic infection during infancy on cognition in late childhood: a follow-up study. Lancet 359: 564-571.

Cacciò S.M., De Giacomo M., Pozıo E. 2002: Sequence analysis of the $\beta$-giardin gene and development of a polymerase chain reaction-restriction fragment length polymorphism assay to genotype Giardia duodenalis cysts from human faecal samples. Int. J. Parasitol. 32: 1023-1030.

Castro-Hermida J.A., García-Presedo I., González-WarLeta M., Mezo M. 2011: Prevalence of Cryptosporidium and Giardia in roe deer (Capreolus capreolus) and wild boars (Sus scrofa) in Galicia (NW Spain). Vet. Parasitol. 179: 216-219.

Chmiel S. 2009: Hydrochemical evaluation of dystrophy of the water bodies in the Łęczna and Włodawa area in the years 2000 2008. Limnol. Rev. 9: 153-158.
Farzan A., Parrington L., Coklin T., Cook A., Pintar K., Pollari F., Dixon B. 2011: Detection and characterization of Giardia duodenalis and Cryptosporidium spp. on swine farms in Ontario, Canada. Foodborne Pathogens Dis. 8: 1207-1213.

Feng Y., XiaO L. 2011: Zoonotic potential and molecular epidemiology of Giardia species and giardiasis. Clin. Microbiol. Rev. 24: $110-140$.

Hamnes I.S., GJerde B.K., Robertson L.J. 2007: Occurrence of Giardia and Cryptosporidium in Norwegian red foxes (Vulpes vulpes). Vet. Parasitol. 143: 347-353.

Hamnes I.S., Gjerde B., Robertson L., Vikøren T., HandeLAND K. 2006: Prevalence of Cryptosporidium and Giardia in free-ranging wild cervids in Norway. Vet. Parasitol. 141: 30-41.

Hanson K.L., Cartwright C.P. 2001: Use of an enzyme immunoassay does not eliminate the need to analyze multiple stool specimens for sensitive detection of Giardia lamblia. J. Clin. Microbiol. 39: 474-477.

Khan S.M., Debnath C., Pramanik A.K., Xiao L., Nozaki T., GANGUly S. 2011: Molecular evidence for zoonotic transmission of Giardia duodenalis among dairy farm workers in West Bengal, India. Vet. Parasitol. 178: 342-345.

Kloch A., Bednarska M., Bajer A. 2005: Intestinal macro- and microparasites of wolves (Canis lupus L.) from north-eastern Poland recovered by coprological study. Ann. Agric. Environ. Med. 12: 237-245.

Krukowska R., Krukowski M. 2009: Assessment of tourism attractivenes of Łęczna-Włodawa Lake District. Annales UMCS, Geographia, Geologia, Mineralogia et Petrographia 64: 77-96.

NIPH-NIH 2014: National Institute of Public Health - National Institute of Hygiene in Poland, Department of Epidemiology, Epidemiological reports "Infectious diseases and poisonings in Poland" (2004-2014), www.pzh.gov.pl.

Paziewska A., Bednarska M., Niewęglowski H., KarBowiak G., Bajer A. 2007: Distribution of Cryptosporidium and Giardia spp. in selected species of protected and game mammals from North-Eastern Poland. Ann. Agric. Environ. Med. 14: 265-270. 
Read C.M., Monis P.T., Thompson R.C.A. 2004: Discrimination of all genotypes of Giardia duodenalis at the glutamate dehydrogenase locus using PCR-RFLP. Infect. Genet. Evol. 4: 125-130.

Rickard L.G., Siefrer C., Boyle C.R., Gentz E.J. 1999: The prevalence of Cryptosporidium and Giardia spp. in fecal samples from free-ranging white-tailed deer (Odocoileus virginianus) in the southeastern United States. J. Vet. Diagn. Investig. 11: $65-72$.

Rimhanen-Finne R., Enemark H.L., Kolehmainen J., Toropainen P., HÄNninen M.L. 2007: Evaluation of immunofluorescence microscopy and enzyme-linked immunosorbent assay in detection of Cryptosporidium and Giardia infections in asymptomatic dogs. Vet. Parasitol. 145: 345-348.

Robertson L.J., Forberg T., Hermansen L., Hamnes I.S., GJERDE, B. 2007: Giardia duodenalis cysts isolated from wild moose and reindeer in Norway: genetic characterization by PCR-rflp and sequence analysis at two genes. J. Wildl. Dis. 43: 576-585.

Ryan U., Cacciò S.M. 2013: Zoonotic potential of Giardia. Int. J. Parasitol. 43: 943-956.

Schrader C., Schielke A., Ellerbroek L., Johne R. 2012: PCR inhibitors - occurrence, properties and removal. J. Appl. Microbiol. 113: 1014-1026.

Received 2 February 2015
SOLARCZYK P. 2009: [Occurrence of Giardia species and genotypes in humans and animals in Wielkopolska region, Poland.] Wiad. Parazytol. 55: 459-462. (In Polish.)

Stojecki K., Sroka J., Karamon J., Kusyk P., Cencek T. 2014: The influence of selected stool concentration techniques for the effectiveness of PCR examination in Giardia lamblia diagnostics. Pol. J. Vet. Science. 17: 231-237.

Traub R.J., Monis P.T., Robertson I., Irwin P., Mencke N., THOMPSON R.C.A. 2004: Epidemiological and molecular evidence supports the zoonotic transmission of Giardia among humans and dogs living in the same community. Parasitology 128 : 253-262.

Veronesi F., Passamonti F., Cacciò S., Diaferia M., Piergili Fioretti D. 2010: Epidemiological survey on equine Cryptosporidium and Giardia infections in Italy and molecular characterization of isolates. Zoonoses Publ. Hlth. 57: 510-517.

Weitzel T., Dittrich S., Möhl I., Adusu E., Jelinek T. 2006: Evaluation of seven commercial antigen detection tests for Giardia and Cryptosporidium in stool samples. Clin. Microbiol. Infec. 12: 656-659.

Wojtyniak B., Goryński P., Moskalewicz B. 2012: [The current state of public health and its determinants in Poland]. Narodowy Instytut Zdrowia Publicznego - Państwowy Zakład Higieny, Warszawa 2012, 191 pp. (In Polish.) 